\title{
Investigating the dynamic response of a punch to human head using finite element analysis
}

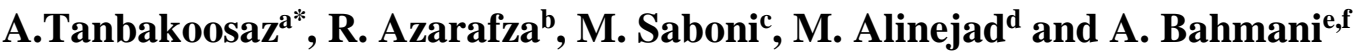

\author{
${ }^{a}$ Department of Engineering, Abhar Branch, Islamic Azad University, Abhar, Iran \\ ${ }^{b}$ Department of Mechanical Engineering, Malek Ashtar University of Technology, Tehran, Iran \\ ${ }^{c}$ Department of Mechanical Engineering, Sanandaj Branch, Islamic Azad University, Sanandaj, Iran \\ ${ }^{d}$ Whshu Federation of I. R. Iran, Tehran, Iran \\ ${ }^{e}$ Department of Sport Engineering, Science and Research Branch, Islamic Azad University, Tehran, Iran \\ ${ }^{f}$ Department of research and development, McGuil Inc, Tehran, Iran
}

\begin{tabular}{|c|c|}
\hline $\begin{array}{l}\text { ARTICLE INFO } \\
\end{array}$ & A B S TRACT \\
\hline $\begin{array}{l}\text { Article history: } \\
\text { Received } 6 \text { January, } 2015 \\
\text { Accepted } 5 \text { May } 2015 \\
\text { Available online } \\
6 \text { May } 2015 \\
\text { Keywords: } \\
\text { Finite element analysis } \\
\text { Shear stress } \\
\text { Punch } \\
\text { Sanda protective helmet }\end{array}$ & $\begin{array}{l}\text { Head injuries are among the dangerous injuries which are common in all sport types. In the } \\
\text { present study, the dynamic response of a punch to the head of a Wushu fighter was simulated } \\
\text { by modeling the human head in ABAQUS software. Moreover, the maximum displacement } \\
\text { and the stress distribution in the helmet and head parts were analyzed by finite elements } \\
\text { method. The obtained results showed a significant interval in the response of different tissues } \\
\text { to the delivered blow. The maximum shear stress, normal stress and displacement in the helmet } \\
\text { were } 5.616 \mathrm{MPa}, 5.755 \mathrm{MPa} \text { and } 1.236 \mathrm{~mm} \text {, respectively, while these magnitudes were } \\
\text { respectively } 3.199 \mathrm{MPa}, 6.268 \mathrm{MPa} \text { and } 0.0001867 \mathrm{~mm} \text { in skull, } 4.596 \mathrm{MPa}, 3.691 \mathrm{MPa} \text { and } \\
0.1180 \mathrm{~mm} \text { in the head skin and } 0.01098 \mathrm{MPa}, 0.8779 \mathrm{MPa} \text { and } 0.04993 \mathrm{~mm} \text { in brain. The } \\
\text { present model with its unique features can be a valuable and powerful instrument to gain a } \\
\text { better insight into the injury mechanism for better diagnosing of injuries and to design } \\
\text { protective helmets with higher efficiency and safety for various sport forms as well. }\end{array}$ \\
\hline
\end{tabular}

\section{Introduction}

Brain damage due to a blow to head is a serious and important social and public health problem and has attracted the attention of many researchers in recent years (Chen, 2011). These injuries may occur in some cases without any apparent brain damage but may lead to severe cerebral damages, unconsciousness and finally death. The athletes in fighting sports like boxing, karate, taekwondo and wushu are exposed to hard blows to head induced by repeated and targeted blows to rival's body and mainly to the head. Superficial brain injuries due to blows are very common in these sports. Most of brain injuries and traumas occur due to direct and repeated blows from near distances to the head in martial arts competitions. Although these repeated blows may seemingly have no alarming primary

* Corresponding author

E-mail addresses: tanbakoosaz.Ali@abhariau.ac.ir (A.Tanbakoosaz) 
effects, they cause repeated traumas in brain inside the skull and this result in internal bleeding and finally serious problems which lead in some cases to death. When a hard blow is delivered to head, there may be no apparent bleeding or skull fracture, but that blow may have caused an internal cerebral damage which may further lead to contusion, blood vessel rupture or damage to cranial nerves. Most of the previous studies have investigated the blow to head and the biomechanics of damages sustained following concussion due to traffic accidents or incidents in sports like football and few studies have dealt with concussions due to direct punches to head and repeated blows for getting points in martial arts competitions. Walilko et al. (2005) investigated the force of the direct punches of seven Olympic boxers in five various weight classes using a three dimensional model and calculated the average linear and angular acceleration and reached to a criterion for cerebral damage. Viano et al. (2005) studied the punch force of eleven Olympic boxers with a 3D model. They investigated not only the direct punch but also hook and uppercut blows in this study and came to the result that punches cause less injuries because of the short time of accelerating and hence do not meet the criterion for brain damage in short time. Al-Bsharat et al. (1999) used a 3D skull model to investigate the role of impact velocity in the magnitude of produced cranial stress during a front strike. They obtained the magnitudes of contact force and intracranial pressure for the applied force.

Zong et al. (2006) presented a 3D finite element model of human head in their study and analyzed it to assess the possibility of head injury due to the applied blows. The high possibility of spinal cord injury as a result of the wave of movement inside the head was also analyzed in this study. Johnson and Young (2005) created a model to simulate the human head response to blow and evaluate the sensitivity of the model to different parameters. For timely simulation of a blow to head which causes cerebral damages, Khurana et al. (2012) reviewed the scientific literature on sport accidents and causes, pathophysiology, assessment short-term and long-term consequences of concussion. Pinnoji and Mahajan (2006) used a finite element model of a front blow to head covered with helmet to investigate the effect of foam thickness on contact forces, pressure and energy absorption during the strike. Stern et al. (2011) carried out a study to investigate the long-term consequences of trauma as a result of repeated blows. They also concentrated on risk factors and in vivo diagnosis.

Asgharpour et al. (2014) analyzed the blow to head of human cadaver using a 3D finite element model. Despite of having a relatively perfect finite element model of human head, they have selected either inefficient or unsuitable mechanical properties for different parts of their model. Post et al. (2011) analyzed a finite element model to study the effect of loading curves on prediction of brain damage. This research used the mentioned model to analyze three loading curves applied independently in each axis of linear and angular acceleration investigated and validated their effects on the prediction of concussion. In the present study some factors including the displacement, normal stress and the shear stress produced by a punch to the head of a Wushu practitioner wearing a Sanda helmet is simulated and analyzed using finite element modeling. The areas and planes of maximum stress and displacement in each tissue were also determined. Additionally, as mentioned before the cerebrospinal fluid has been rarely taken into account in the previous papers as hydro elastic fluid. For eliminating some of these deficiencies a 3D finite element model was employed with viscoelastic materials in the model of human head which defined by related Perony series and the cerebrospinal fluid was considered as a hydrostatic fluid to increase the accuracy of the used finite element model in comparison with the other previous models.

\section{Material and Method}

The applied punch force to the head leads to a series of complex physical and mechanical reactions such as local bending of skull, volumetric changes of intracranial contents, propagation of blow waves in whole brain and inertial effects. All these effects force the tissue to change its state and may further lead to the damage of head skin, skull, blood vessels and brain (Motherway et al., 2009). 


\subsection{Model geometry}

CT scan images and CMM laser of a 25-year-old wushu fighter were used in this study to create the geometry of human head model. Using a CMM laser device (optical laser), the point cloud of head, face and helmet was obtained. The files of the athlete's head CT scan images were loaded in MIMICS software to separate brain, cerebrospinal fluid and skull (Fig.1). As the CMM laser device cannot determine the head skin thickness, SolidWorks software was used in this study to determine the thickness of the head skin, to separate the cerebrospinal fluid and to transform the obtain points cloud to a solid shape. The simulated model in this study contains four parts of Sanda helmet, head skin, skull and cerebrospinal fluid. Fig. 2 shows a section of whole model.
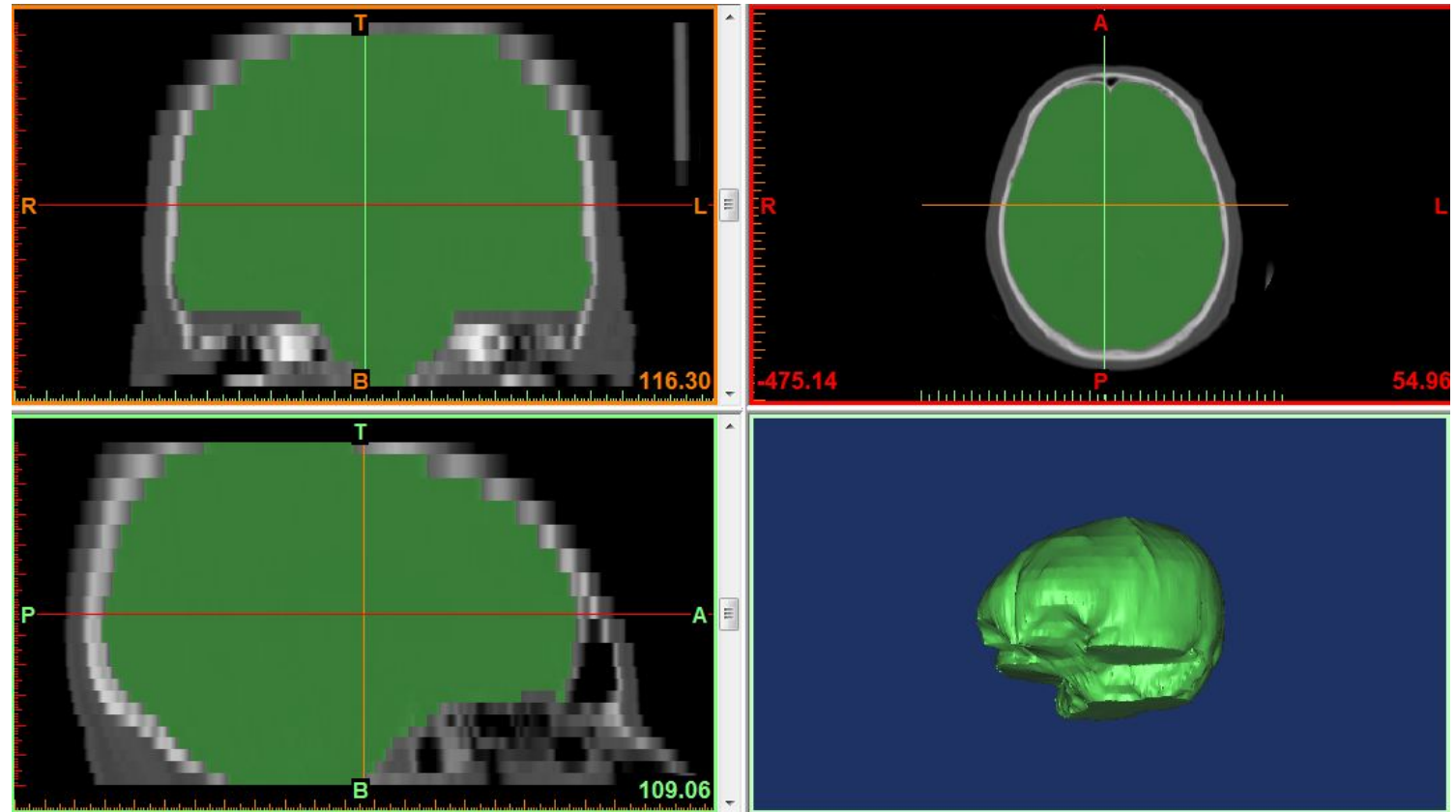

Fig.1. CT Scan images and the Three-dimensional model modified by Mimics 10 software

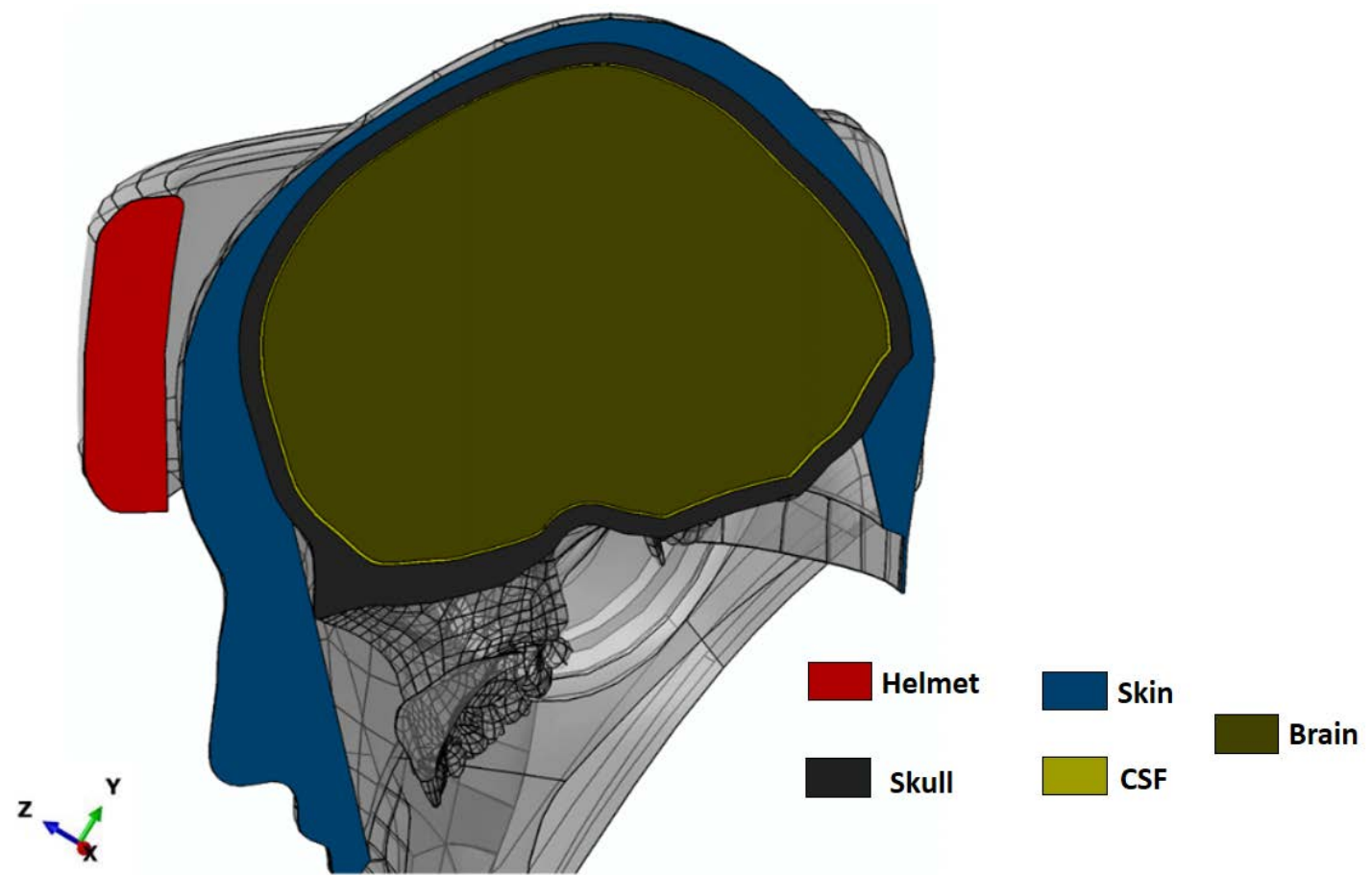

Fig. 2. Section of the whole model of the head covered with helmet 


\subsection{Mechanical properties of model}

Mechanical properties of the membrane processes, head skin and face were adopted from data obtained by Yan et al. (2011) as presented in Table 1. The helmet was made of high density Ethylene Vinyl Acetate (EVA) foam and its mechanical properties were obtained from Martienssen and Warlimont (2006) as presented in Table 2.

Table 1. Mechanical properties of various tissues in head model (Yan et al., 2011)

\begin{tabular}{llllllll}
\hline Layers & Sub-layers & $\begin{array}{l}\text { Behavior } \\
\text { Of materials }\end{array}$ & $\begin{array}{l}\text { Thickness } \\
(\mathrm{mm})\end{array}$ & $\begin{array}{l}\text { Density } \\
\left(\mathrm{kg} / \mathrm{m}^{3}\right)\end{array}$ & $\begin{array}{l}\text { Long-term } \\
\text { modulus } \\
\text { of elasticity (MPa) }\end{array}$ & $\begin{array}{l}\text { Bulk } \\
\text { modulus } \\
(\mathrm{MPa})\end{array}$ & $\begin{array}{l}\text { Poisson's } \\
\text { Ratio }\end{array}$ \\
\hline Skin & Skin & Elastic & 5 & 11.30 & 16700 & 35 & 0.42 \\
Skull & Skull bone & Viscoelastic & 10 & 2500 & 5000 & 3086 & 0.23 \\
Cerebrospinal fluid & CSF & Fluid & 1.3 & 1000 & - & 22 & 0.5 \\
Brain & $\begin{array}{l}\text { Grey matter white } \\
\text { matter }\end{array}$ & Viscoelastic & - & 1060 & 0.123 & 2278 & 0.49 \\
\hline
\end{tabular}

Table 2. Mechanical properties of EVA foam in helmet model (Martienssen and Warlimont, 2006)

\begin{tabular}{llllll}
\hline $\begin{array}{l}\text { Behavior } \\
\text { Of materials }\end{array}$ & $\begin{array}{l}\text { Density } \\
\left(\mathrm{g} / \mathrm{cm}^{3}\right)\end{array}$ & $\begin{array}{l}\text { Modulus of } \\
\text { Elasticity E (GPa) }\end{array}$ & $\begin{array}{l}\text { Poisson's } \\
\text { Ratio }\end{array}$ & $\begin{array}{l}\text { Shear } \\
\text { Modulus G (GPa) }\end{array}$ & $\begin{array}{l}\text { Weight } \\
(\mathrm{Kg})\end{array}$ \\
\hline Elastic & 0.95 & 0.8 & 0.4 & 0.85 & 0.3 \\
\hline
\end{tabular}

The skull bone was simulated as a viscoelastic material and the cerebrospinal fluid was considered as a hydrostatic fluid. In viscoelastic conditions, the relaxation (current) shear modulus $G_{R}(t)$ is determined by the following dimensionless function, $g_{R}(t)$, expressed as a Prony series (Yan et al. 2011):

$$
g_{R(t)}=1-0.8150 \times\left(1-e^{-t / 0.00143}\right),
$$

where $g_{R}(t)=G_{R}(t) / G_{0}$ and $G_{0}$ are the instantaneous shear modulus. As time approaches infinity, the long-term modulus can be obtained from the following Perony series as:

$$
G \infty=G_{R}(\infty)=g_{R}(\infty) \times G_{0}
$$

The elastic modulus $E$, the shear modulus $G$ and Poisson's ratio $v$, at any time, are related by the following well-known relationship:

$$
G=\frac{E}{2(1+v)}
$$

The Bulk modulus $(K)$ is determined by:

$$
K=\frac{E}{3(1-2 v)}
$$

\subsection{Modeling and loading due to punch on helmet}

ABAQUS software was used for modeling and analysis. Fig. 3 shows the generated model with the applied blow, boundary conditions and the whole mesh for analysis as well. 


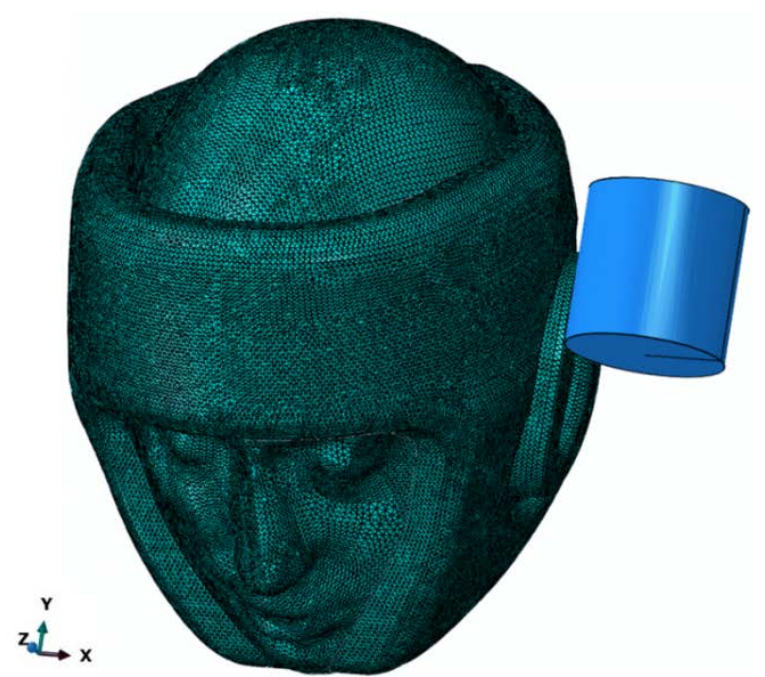

Fig. 3.The generated model with the applied blow, boundary conditions and meshes

The model of human head with helmet was used in the present study to analyze the strike phenomenon which is a dynamic strike. The mechanical properties for modeling were adopted from previous studies. As seen from Fig. 3, blow is hit from left to athlete's head and loading duration is 0.03s. The loadingtime diagram, which is seen in Fig. 4, was adopted from the study of Walilko et al. (2005). From two available contact types the general contact and surface to surface contact without friction was chosen. For the sake of high accuracy and correctness of responses, we constrained the degrees of freedom of the origin of rigid puncher in all directions except for $\mathrm{x}$ direction and as boundary conditions, the locations under helmet, under athlete's head and chin (i.e. neck) were fixed. A fixed neck simulates the real and natural state of human head in the model. The complexity of the model has increased due to the variation of selected materials. 2963136 C3D4 elements were selected for analysis. Due to complex geometry of this analysis, prismatic or tetrahedral meshes were used. The analysis results are presented below.

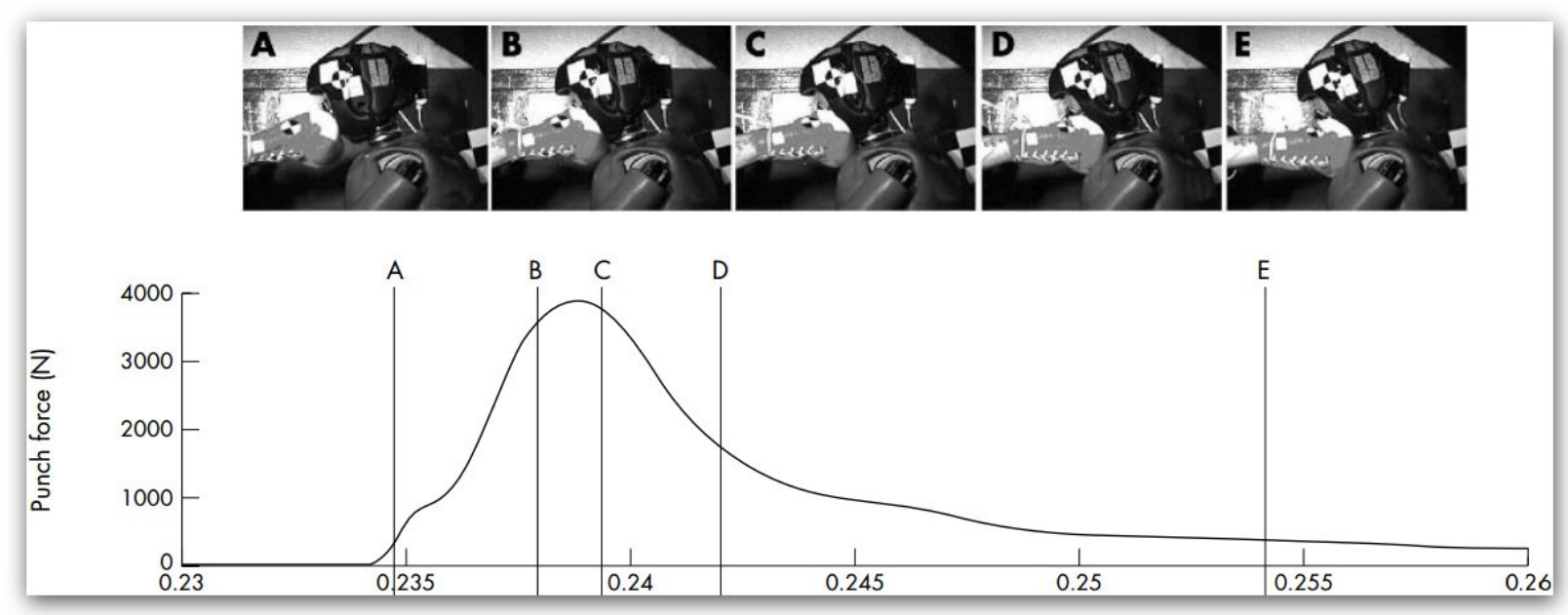

Fig .4. The Punch dynamics duration diagram (Walilko et al., 2005)

\section{Results}

Table 3 shows the results of stress analysis considering the cerebrospinal fluid (present study) and without considering the cerebrospinal fluid (Johnson et al., 2005). By comparing the obtained stresses, the effect of cerebrospinal fluid on the magnitude of stress applied to the brain (i.e. the damping effect of the cerebrospinal fluid) becomes clear. 
Table 3. Comparison of stress values with (i.e. present study) and without considering the cerebrospinal fluid

\begin{tabular}{lll}
\hline $\begin{array}{l}\text { The percentage of difference } \\
\text { in the applied Von Mises stresses }\end{array}$ & $\begin{array}{l}\text { The obtained stress in } \\
\text { the present study (MPa) }\end{array}$ & $\begin{array}{l}\text { The obtained stress by } \\
\text { Johnson et al. (MPa) }\end{array}$ \\
\hline $72 \%$ & 0.01229 & 0.0445 \\
\hline
\end{tabular}

Table 4. The magnitudes obtained for maximum stress and displacement of different tissues of head and helmet

\begin{tabular}{lllll}
\hline layers & Helmet & Skin & Skull & Brain \\
\hline $\begin{array}{l}\text { Maximum shear } \\
\text { stress }(\mathrm{MPa})\end{array}$ & 5.616 & 4.596 & 3.199 & 0.01098 \\
$\begin{array}{l}\text { Maximum normal } \\
\text { stress }(\mathrm{MPa})\end{array}$ & 5.755 & 3.691 & 6.268 & 0.8779 \\
$\begin{array}{l}\text { Maximum } \\
\text { displacement }(\mathrm{mm})\end{array}$ & 1.236 & 0.1180 & 0.0001867 & 0.04993 \\
\hline
\end{tabular}

In this study, the impact duration was considered $0.03 \mathrm{~s}$ according to Fig. 3. The maximum forced conducted to the model was about $400 \mathrm{~N}$ and occurred in the time interval from B to C. Results in Table 3 indicate that a smaller magnitude of impact is transferred to inner side of helmet as presented in Fig. 5. The magnitude of displacement in brain tissue in $y-z$ plane is more than in other alignments. The maximum displacement of brain tissue is seen in Fig. 6. The maximum displacement of skull tissue, like the maximum displacement of brain tissue, occurred in the front part of the head, as shown in Fig. 7. The analysis of head skin displacement revealed that the maximum displacement of skin tissue is occurred in the location where the punch struck the helmet. Fig. 8 shows this maximum magnitude. The measurement units of stress and displacement in all figures are $\mathrm{MPa}$ and $\mathrm{mm}$, respectively. It should be noted that the whole displacement contours in Figs. 5 to 8 are in mm.

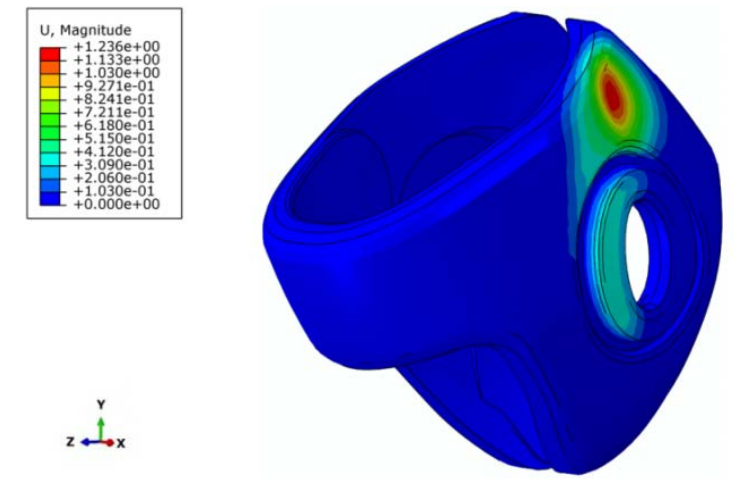

Fig. 5. Magnitude of displacement in helmet.

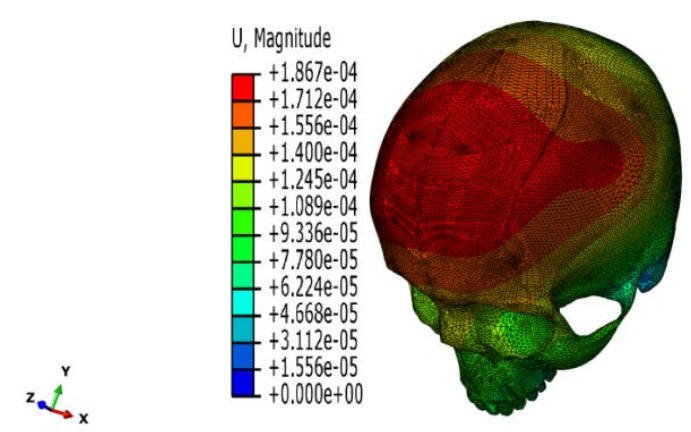

Fig. 7. Magnitude of displacement in skull tissue.

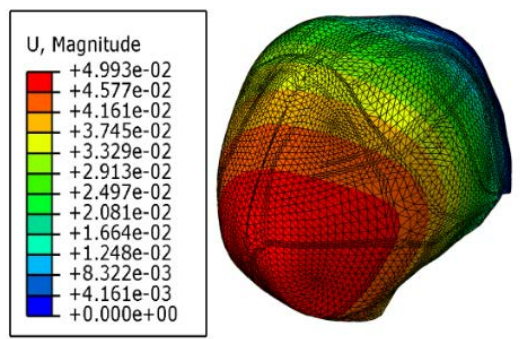

$\stackrel{\text { L }}{\text { L }}$

Fig.6. Displacement in brain tissue.
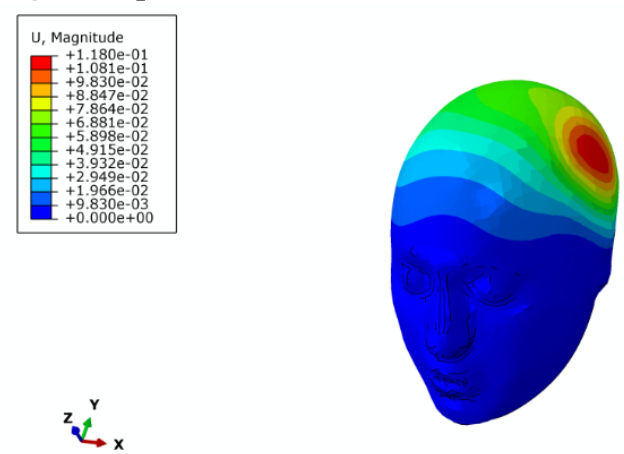

Fig. 8. Magnitude of displacement in skin tissue. 
Results show that the magnitude of displacement in helmet was higher than other tissues. Among the head tissues, however, the maximum displacement was occurred in skin and its value was $0.18 \mathrm{~mm}$ as shown in Fig. 8. The results of stresses in helmet and head tissues have been presented in Figs. 8 to11, in which the unit of all stress contours is MPa. The magnitude of normal stress in the impact area in helmet was much lower than the other areas of helmet in all three directions of $\mathrm{x}, \mathrm{y}$ and $\mathrm{z}$. Also the magnitude of normal stress in the helmet was in $\mathrm{z}$ direction higher than that in other directions. Fig. 9 shows the magnitude and the distribution of normal stress which are almost the same in all directions. Furthermore, the normal stress contour in $\mathrm{x}$ and $\mathrm{y}$ directions in skull was almost the same in all areas except for impact area, but interestingly, the magnitude of normal stress in z direction of the impact area was less than $x$ and $y$ directions, as seen in Fig. 10. The minimum normal stress was occurred in the $y$ direction of impact area. The most affected areas in the $\mathrm{z}$ direction were around the ear and eye regions as shown in Fig. 11 but for skin tissue, the maximum normal stress was occurred in $\mathrm{x}$ direction (see Fig. 12).

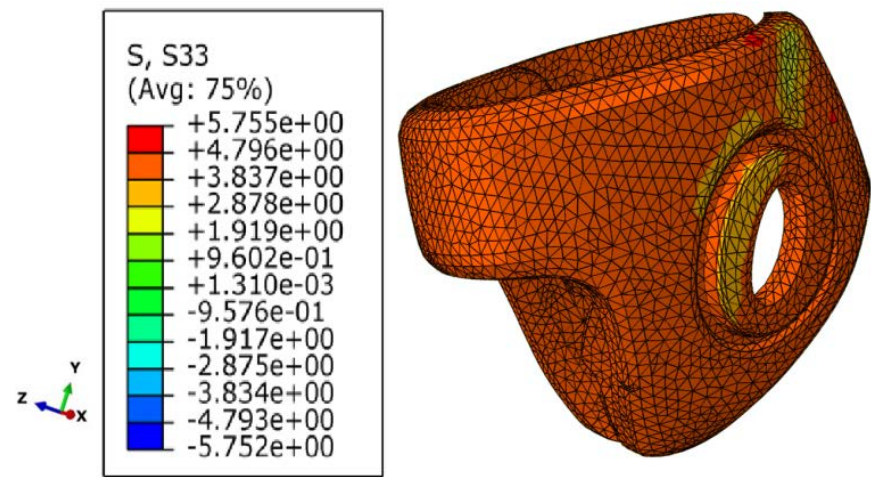

Fig. 9. Magnitude and distribution of normal stress in helmet, in $\mathrm{z}$ direction.

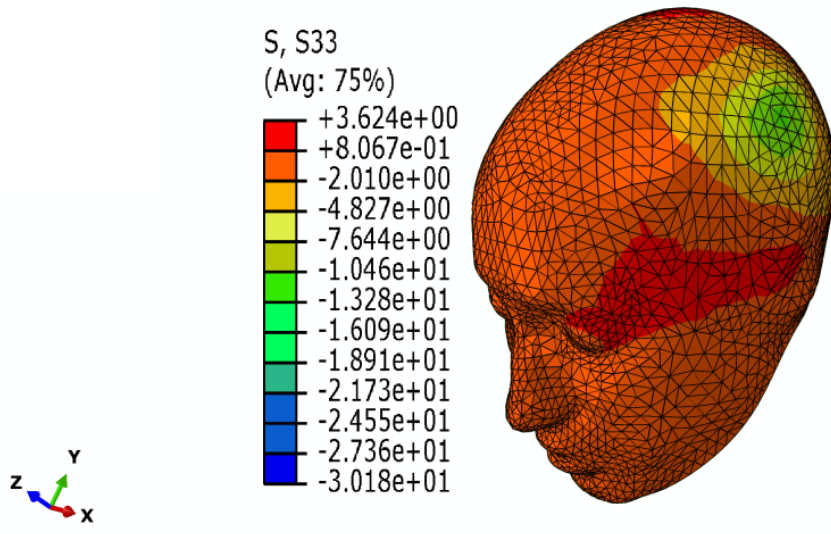

Fig. 11. Distribution of normal stress in $\mathrm{z}$ direction in face (on eye and ear).

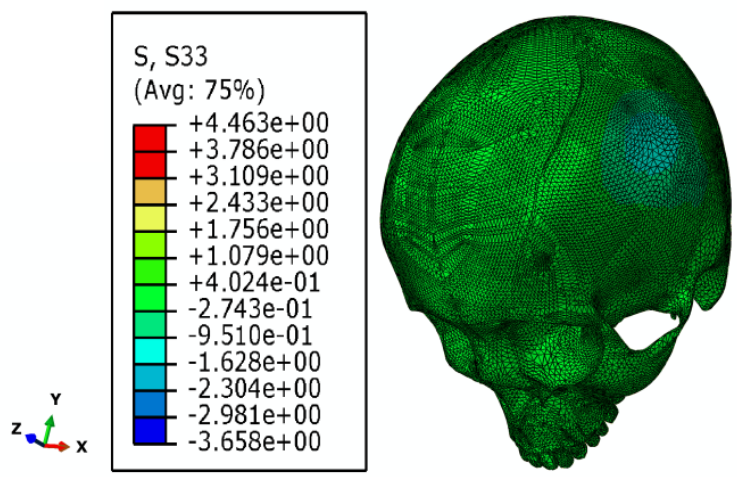

Fig. 10. Magnitude and distribution of normal stress in skull, in z direction.

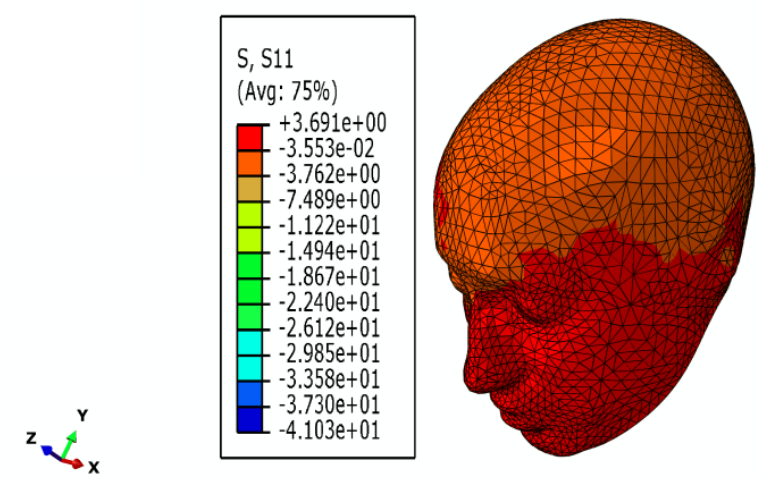

Fig. 12. Distribution of normal stress in skin tissue, in $\mathrm{x}$ direction.

A different trend than that of normal stresses was observed for distribution of shear stresses. Finite element simulations revealed that shear stress is the main reason of injuries in brain and other tissues, since the magnitude of shear stresses were noticeably higher than the normal stress during impact. In helmet, the magnitude of shear stresses in $\mathrm{x}-\mathrm{y}$ and $\mathrm{x}-\mathrm{z}$ planes of impact area was much higher than that of other areas of helmet. However, the intensity of stress distribution in $x-y$ plane is higher than the $x-$ $\mathrm{z}$ plane as seen in Fig. 13. Although the punch was delivered from the lateral side to head, the greatest effect of shear stress in brain tissue is occurred in $\mathrm{x}-\mathrm{z}$ plane. Shear stress distribution in $\mathrm{x}-\mathrm{z}$ plane has been shown in Fig. 14 for the brain tissue. Also in y-z plane the shear stress was smaller than that of $x-$ 
$\mathrm{z}$ plane. The shear stress distribution in $\mathrm{x}-\mathrm{y}$ plane in skull was generally uniform except for the location of impact to skull bone. The shear stress in $\mathrm{x}-\mathrm{z}$ plane of the impact location in skull was also greater than other areas of skull. The shear stress distribution in $\mathrm{y}-\mathrm{z}$ plane of skull was completely different from the shear stress distribution of same plane in brain section. The magnitude of this stress was greater than that in $\mathrm{x}-\mathrm{z}$ and $\mathrm{x}-\mathrm{y}$ planes, as shown in Fig. 15. The shear stress in skin tissue was almost the same in all three directions and its maximum magnitude is in $x-y$ plane, as shown in Fig. 16.
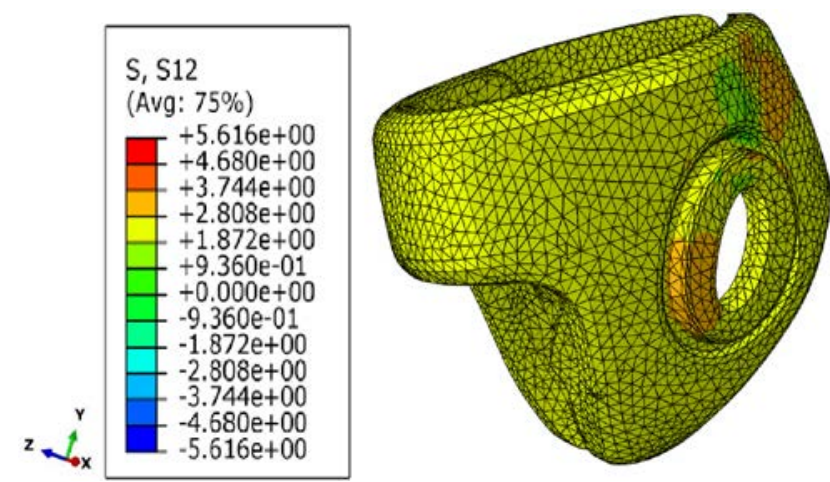

Fig. 13. Magnitude and distribution of shear stress in helmet, in $\mathrm{x}-\mathrm{y}$ plane

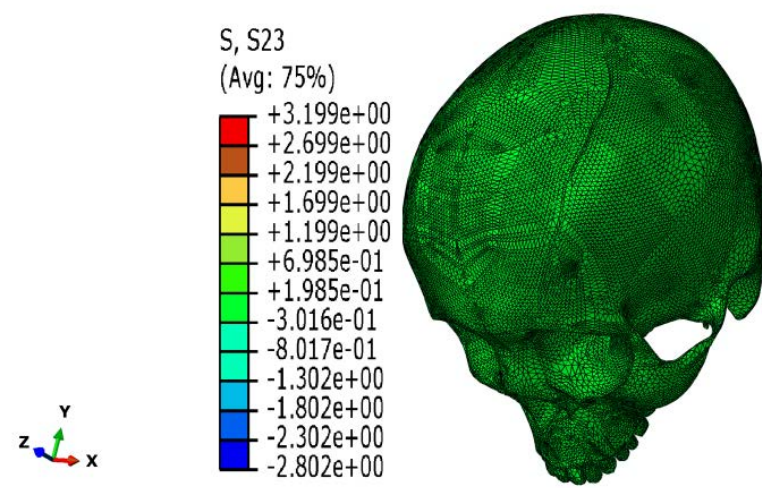

Fig. 15. Distribution of shear stress in $y-z$ plane in skull
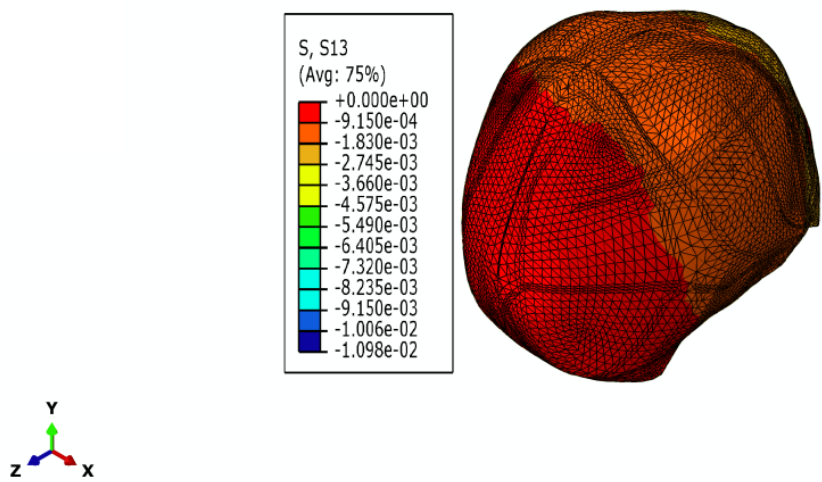

Fig. 14. Magnitude of shear stress of brain tissue in $x-z$ plane

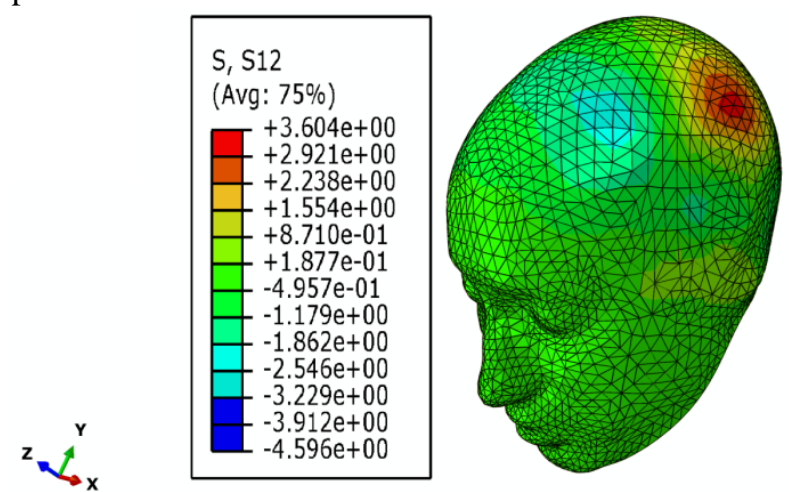

Fig. 16. Distribution of shear stress in head skin in $x-y$ plane

\section{Discussion}

In the present study, either normal stress or shear stress due to a punch to head covered by helmet were investigated using finite element modeling and the critical points in each tissue were determined. researchers have concentrated in previous studies on the generation of a more detailed finite element model which is as far as possible perfect and on defining more appropriate mechanical properties for different parts of the model, however, most of the previous studies have not been considered characteristics and behavior of viscoelastic materials and as well the cerebrospinal fluid and skull layers. By the way, there are few investigations on computing the displacement and stress fields in athletes' head due to punch impact. Furthermore, no finite element model of human head has been generated in previous studies and they have used only dummies or models which simulated merely the overall geometry of human head with various materials. But investigating the effect of an impact to head requires clearly a 3D finite element model. We tried in the present study to make a progress in developing and generating a finite element model of human head for investigating and analyzing impact despite of challenges like complex geometry of various head tissues, composition of head materials, 
boundary conditions, meshing and also lack of required facilities. As no study was performed before to analyze the dynamic response of punch to human head, we had to compare the present study with those having a subject relatively close to ours. Walilko et al. (2005) investigated the force of the direct punches of Olympic boxers to a model of head with boxing helmet. The created model was made of foam. We tried in this paper to obviate this problem by generating a finite element model with proper mechanical properties and calculated the average linear and angular acceleration and hence a criterion for cerebral damage was found. As stated earlier the blow to head of human cadaver using a 3D finite element model was studied by Asgharpour et al. (2014). In their study, characteristics like Peroni series were not defined for the mechanical properties of viscoelastic tissues and this was a shortcoming which was obviated in this study. Viano et al. (2005) studied the punch force of eleven Olympic boxers with a 3D model. Like Walilko et al. (2005), they did not take into account those factors which can render the real mechanical properties of human head tissues. As mentioned above, our model does not have this shortcoming. Finally, the analyses show that the magnitude of displacement in Sanda helmet is greater than that of other tissues. But among the tissues of human head model, the displacement magnitude and distribution in skin tissue at the location where shear stress was produced in $\mathrm{x}-\mathrm{y}$ plane, were greater than other tissues. The magnitude of displacement and distribution of stress in this skin have been presented in Fig. 6. Like displacement, normal stress in Sanda helmet was greater than that in other tissues. Needless to say that there are a number of criteria for predicting the human head injury namely the head injury criterion (HIC) (Gadd, 1966) and the head impact power (HIP) (Newman et al., 2000) based criterion as well as the injury mechanisms related criteria provided by the simulated injury monitor (SIMon) (Takhounts et al., 2003). Moreover, the Louis Pasteur University (ULP) and the Hashin failure criterion (Chang \& Chang, 1987) can be employed for predicting the damage process. Hence using more accurate simulations of this research one can investigate head injuries more precisely by employing the aforementioned criteria. In addition, as entire parameters in the equation of injury criteria the results of this paper could have a crucial role in developing some new criteria for predicting human body injuries in risky circumstances. As an example, the Hashin failure criterion can be written as:

$e_{\text {Comp }}^{2}=\left(\frac{\sigma_{2}}{2 S_{12}}\right)^{2}+\left[\left(\frac{C_{2}}{2 S_{12}}\right)^{2}-1\right] \frac{\sigma_{2}}{C_{2}}+\left(\frac{\tau_{12}}{S_{12}}\right)^{2}$,

where $\sigma_{2}$ and $S_{12}$ are normal stress and shear strength respectively. The $C_{2}$ is transverse compressive strength and $\tau_{12}$ is shear stress. In another approach, producing composite helmets could be influential for protecting the head in different risky conditions. Therefore, regarding the Hashin failure criterion the results of this paper could have essential role in investigating and controlling head injuries in composite helmets.

\section{Conclusion}

In the present study the magnitudes of shear stress, normal stress and displacement field due to blows delivered to head parts during competitions was investigated using a finite element model of human head covered with a helmet of VICING brand. The highest magnitude of force exerted to the model due to punch impact was $4000 \mathrm{~N}$. The impact duration was 0.03 s as seen in the time interval [B-C] in the curve of Fig. 3. Results indicate that the shear stress causes the most damages in various tissues of human head and that the anterior area of brain sustains the most injuries. The highest shear stress in skull occurs in the anterior area of skull. Furthermore, the highest amount of displacement in finite element model of human head was seen in the frontal part of the brain.

\section{Acknowledgement}

The authors would like to thank the anonymous referees for constructive comments on earlier version of this paper. 


\section{References}

Al-Bsharat, A., Zhou, C., Yang, K. H., Khalil, T., \& King, A. I. (1999). Intracranial pressure in the human head due to frontal impact based on a finite element model. ASME-PUBLICATIONS-BED, 42, 113-114.

Asgharpour, Z., Baumgartner, D., Willinger, R., Graw, M., \& Peldschus, S. (2014). The validation and application of a finite element human head model for frontal skull fracture analysis. Journal of the Mechanical Behavior of Biomedical Materials, 33, 16-23.

Chang, F. K., \& Chang, K. Y. (1987). A progressive damage model for laminated composites containing stress concentrations. Journal of Composite Materials, 21(9), 834-855.

Chen, Y. (2011). Biomechanical analysis of traumatic brain injury by MRI-based finite element modeling (Doctoral dissertation, University of Illinois at Urbana-Champaign).

Gadd, C. W. (1966). Use of a weighted-impulse criterion for estimating injury hazard (No. 660793). SAE Technical Paper.

Johnson, E. A. C., \& Young, P. G. (2005). On the use of a patient-specific rapid-prototyped model to simulate the response of the human head to impact and comparison with analytical and finite element models. Journal of Biomechanics, 38(1), 39-45.

Khurana, V. G., \& Kaye, A. H. (2012). An overview of concussion in sport. Journal of Clinical Neuroscience, 19(1), 1-11.

Martienssen, W., \& Warlimont, H. (Eds.). (2006). Springer handbook of condensed matter and materials data. Springer Science \& Business Media.

Motherway, J., Doorly, M. C., Curtis, M., \& Gilchrist, M. D. (2009). Head impact biomechanics simulations: A forensic tool for reconstructing head injury?. Legal Medicine, 11, S220-S222.

Newman, J. A., Shewchenko, N., \& Welbourne, E. (2000). A proposed new biomechanical head injury assessment function-the maximum power index. Stapp Car Crash Journal, 44, 215-247.

Pinnoji, P. K., \& Mahajan, P. (2006, September). Impact analysis of helmets for improved ventilation with deformable head model. In Proceeding of IRCOBI Conference, Madrid (pp. 159-70).

Post, A., Hoshizaki, B., \& Gilchrist, M. D. (2012). Finite element analysis of the effect of loading curve shape on brain injury predictors. Journal of Biomechanics, 45(4), 679-683.

Stern, R. A., Riley, D. O., Daneshvar, D. H., Nowinski, C. J., Cantu, R. C., \& McKee, A. C. (2011). Long-term consequences of repetitive brain trauma: chronic traumatic encephalopathy. $P M \& R, 3(10)$, S460-S467.

Takhounts, E. G., Eppinger, R. H., Campbell, J. Q., Tannous, R. E., Power, E. D., \& Shook, L. S. (2003). On the development of the SIMon finite element head model. Stapp Car Crash Journal, 47, 107-133.

Viano, D. C., Casson, I. R., Pellman, E. J., Bir, C. A., Zhang, L., Sherman, D. C., \& Boitano, M. A. (2005). Concussion in professional football: Comparison with boxing head impacts-Part 10. Neurosurgery, 57(6), 1154-1172.

Walilko, T. J., Viano, D. C., \& Bir, C. A. (2005). Biomechanics of the head for Olympic boxer punches to the face. British Journal of Sports Medicine, 39(10), 710-719.

Yan, W., \& Pangestu, O. D. (2011). A modified human head model for the study of impact head injury. Computer Methods in Biomechanics and Biomedical Engineering, 14(12), 1049-1057.

Zong, Z., Lee, H. P., \& Lu, C. (2006). A three-dimensional human head finite element model and power flow in a human head subject to impact loading. Journal of Biomechanics, 39(2), 284-292. 